\title{
A Three-Stage Hybrid Model for Space-Time Analysis of Water Resources Carrying Capacity: A Case Study of Jilin Province, China
}

\author{
Tong Liu ${ }^{1}$, Xiaohua Yang ${ }^{1, *}$, Leihua Geng ${ }^{2}$ and Boyang Sun ${ }^{1}$ \\ 1 State Key Laboratory of Water Environment Simulation, School of Environment, Beijing Normal University, \\ Beijing 100875, China; cdliutong@mail.bnu.edu.cn (T.L.); 201431180013@mail.bnu.edu.cn (B.S.) \\ 2 Nanjing Hydraulic Research Institute, Key Laboratory of Water Resource and Hydraulic Engineering, \\ Nanjing 210029, China; lhgeng@nhri.cn \\ * Correspondence: xiaohuayang@bnu.edu.cn
}

Received: 5 January 2020; Accepted: 30 January 2020; Published: 5 February 2020

\begin{abstract}
Water shortage, water pollution, shrinking water area and water mobility are the main contents of the water resources crisis, which are widespread in the social and economic development of Jilin Province. In this paper, a three-stage hybrid model integrating evaluation, prediction and regulation is constructed by combining the load-balance method and the system dynamics method. Using this model, the current states of water resources carrying capacity (WRCC) in 2017 and the trend of water demand/available from 2018 to 2030 were obtained. Using the orthogonal test method, the optimal combination program of agricultural and industrial water efficiency regulation and water resources allocation was selected. The results show that the pressure of the human-water resources system in Changchun, Liaoyuan and Baicheng is greater than the support, and the other six cities are not overloaded. The water demand in Jilin Province and its nine cities will increase from 2018 to 2030, if the current socio-economic development pattern is maintained. Therefore, we change the water quantity carrying capacity index by controlling agriculture, industrial water efficiency and trans-regional water transfer. Compared with 2015, among the optimal program obtained, the change range of the water use per 10,000 RMB of agricultural output is $(-5 \%, 25 \%)$, and the water use per $10,000 \mathrm{RMB}$ of industrial added value is $(-45 \%,-35 \%)$, and the maximum water transfer is 1.5 billion $\mathrm{m}^{3}$ per year in 2030. This study analyzes the development pattern of WRCC in the process of water conservancy modernization in Jilin Province and provides reference for other provinces to make the similar plan.
\end{abstract}

Keywords: water resources carrying capacity; load-balance; system dynamics model; water resources allocation; Jilin province

\section{Introduction}

As a precious natural resource, water plays an important role for the survival and development of human society. As the population grows, the demand for water resources is increasing, and water resources problems such as water shortage and water pollution are becoming more and more prominent [1-3]. There are two human causes of water resources problems. First, there is too much water for living and production, but less water for ecological environment, resulting in the failure of basic ecological flow and water area of rivers and lakes. Secondly, the amount of pollutants discharged from the socio-economic system exceeds environmental capacity. Therefore, the total volume of natural water resources consisting of non-renewable water resources and renewable water resources is calculated, which is used to solve the problem of water shortage [4-6]. In addition, water quality models are often used to simulate the diffusion process of pollutants in the water environment 
to calculate environmental capacity, thereby solving the problem of water pollution [7-9]. For the sustainable development of human-water resources system (HWRS), the rational allocation of water resources is essential [10,11].

Jilin Province benefited from abundant natural resources and a good industrial base. Before the 1990s, it had been China's most important industrial base for a long time, and its economic development level was at the forefront of the country. However, due to the contradiction of system and structure, the economy of Jilin has shown a severe decline since the end of the last century. In recent years, with the implementation of the strategy of revitalizing Northeast China, the demand for water resources in Jilin has been increasing, and the regional water resource load balance has gradually shifted. Considering the water resources crisis and water conservancy modernization plan of Jilin Province, this study analyzes the water resources carrying capacity (WRCC) of Jilin Province. Through orthogonal experiments, a regulation plan in Jilin Province was obtained, and comprehensive suggestions for improving WRCC in Jilin Province were put forward.

The remainder of this article is arranged as follows: the second section presents the literature review; the third section includes the study area and data sources; the fourth section presents the three-stage hybrid model; the fifth section presents the results; the sixth section presents the discussion, and the last section presents the conclusions.

\section{Literature Review}

The term "carrying capacity" is derived from ecology, which is used to measure the largest organisms that a specific region can support for some period of time without obvious adverse effect on the local environment [12]. After that, the application field of carrying capacity continued to expand, and the ecological carrying capacity [13], environmental carrying capacity [14], land carrying capacity [15], and mineral resources carrying capacity [16] appeared one after the other. WRCC is an extension of the concept of carrying capacity in the field of water resources, which focuses on the interaction between the human system and the water resources system. Since the introduction of the concept of WRCC, a lot of fruitful research results have been published. However, it is difficult to find a well recognized definition of WRCC. (i) WRCC is the largest external activity that water resources can carry out [17], which only exists in theory, without relevant quantitative study. (ii) WRCC is a threshold, such as the largest amount of local water resources [18], the largest economic scale and the population that can be supported by local water resources $[19,20]$. At present, economic and population scales are often used as indicators of WRCC. Obviously, forces always appear in pairs in physics, so the carrying capacity can be divided into support ability and pressure ability. By comparing their values, the carrying states of the water resources can be diagnosed. Wang et al. judged that Tianjin 's water resources system was overloaded by comparing the WRCC with the actual population [21].

A complete and reasonable index system is essential for studying the WRCC [22,23]. At present, water environment, water resources, and social-economy that are closely related to the HWRS are usually included in the index system, and then three criteria layer layers are obtained [24-26]: (i) The water resources standard layer mainly reflects the ability of the local water resources subsystem to supply water to the socio-economic subsystem. (ii) The water environment standard layer is closely related to the water environment capacity. (iii) The socio-economic standard layer mainly contains elements in human production and living activities. In general, due to the concept of traditional WRCC, the indicators in the above-mentioned criterion layer are mostly related to water quantity and water quality, but the interaction in the HWRS is far more than them. Water intake and sewage discharge activities are generated by the socio-economic subsystem, causing damage and interference to the space of water ecological and hydrological processes of the water resources-environment subsystem, and thus generating pressure. In addition, the water resources-environment subsystem generates support through water supply and consumption of pollutants. It can be seen that in order to maintain the sustainable development of the HWRS, it is necessary to obtain multi-element support of water resources, such as quantity, quality, space, and flow. 
The study of WRCC, which includes evaluation, prediction and regulation, is based on evaluation, using prediction as a starting point, and achieving the goal through regulation. The focus of the evaluation is to quantify the carrying capacity of a specific region [27]. Predictive research usually sets different development scenarios for the HWRS, and then predicts the WRCC of each scenario [28]. The research on regulation refers to planning, such as water environment protection planning and water resources development planning, and then the target of WRCC is set. The positive and negative feedback effects in the HWRS are used to regulate the activities of social and economic, and finally, the carrying capacity is in line with the expected target [29]. In general, whether it is evaluation, prediction or regulation, the results of WRCC research can provide reference for regional socio-economic development and water resources protection, but the scope is limited. The WRCC of 36 major Chinese cities has been evaluated [26,30]. These research results can reflect the past or current water resources carrying states. In order to study the WRCC of a specific region in the future, evaluation studies can be combined with predictive research. For example, Yang et al. predicted the WRCC of Xi'an in 2020 [31]. Usually, the prediction research needs to set up multiple scenarios and obtain the prediction results of WRCC and then get the regulation programs. These regulation programs are mostly derived from the parameter settings in the prediction scenario, which has the best simulation result. If the regulation is carried out according to these programs, there will often be an excess of support ability, resulting in high economic costs of regulation and low feasibility. In addition, the research on the development of HWRS shows that the carrying condition of water resources in a specific region is different in different historical stages and narrowing the evaluation of the carrying capacity in the long-term span is a key problem to be solved. Therefore, a three-stage hybrid model was established to study the WRCC in Jilin Province.

\section{Study Area and Date Sources}

\subsection{Study Area}

Jilin Province is located at longitude $121^{\circ} 38^{\prime}-131^{\circ} 19^{\prime} \mathrm{E}$ and latitude $40^{\circ} 50^{\prime}-46^{\circ} 19^{\prime} \mathrm{N}$. It covers an area of $187,400 \mathrm{~km}^{2}$, including eight prefecture-level cities and one autonomous prefecture, as shown in Figure 1. Jilin Province is an important industrial base and commodity grain base in China. With the strategy of revitalizing the northeast old industrial base and the modernization of water conservancy, socio-economic development has brought a lot of pressure on the water resources [32]. There are 19 major rivers in Jilin Province, which belong to five water systems [33]. These rivers transport a lot of water resources for Jilin Province. However, the volume of water resources per capita in Jilin Province is insufficient. As shown in the "Jilin Provincial Water Resources Bulletin (2017)", the regional volume of water resources per capita is only $1451.5 \mathrm{~m}^{3}$, which is a water-stressed area [34]. In addition, approximately 1.12 billion tons of wastewater was discharged into water bodies in 2017. Therefore, surface water pollution has caused deterioration of the water environment. The shortage of water resources and pollution of the water environment have severely restricted the sustainable development of society and economy in Jilin [35].

The east of Jilin is rich in rainfall and rich in water resources, which is the birthplace of many rivers. The central part of Jilin is an important commodity grain production base in China, consuming a lot of water resources. The grasslands in the west of Jilin are vast, with large wetlands and abundant groundwater and transit water, but the excessive exploitation of groundwater extraction has caused wetland degradation and ground subsidence [36]. The spatial and temporal distribution of water resources in Jilin Province is uneven [37]. Thus, the water resource problems in Jilin Province are produced by both social and natural factors, which pose an urgent problem for the government and researchers. 


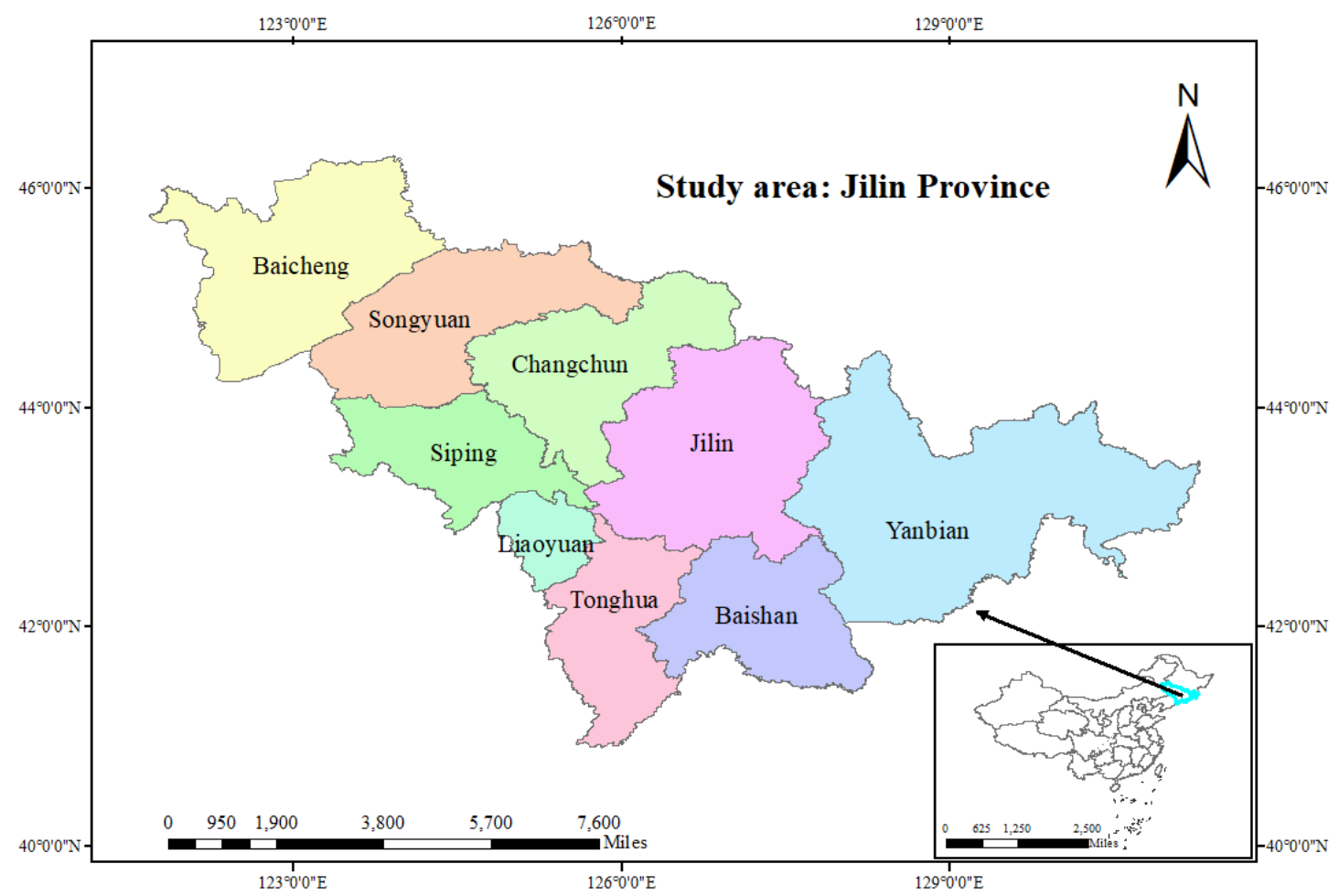

Figure 1. Location of Jilin Province.

\subsection{Date Sources}

The major datasets used in this study include water demand, water available, water conservation, population and economic. Table 1 presents all the data used in the study and their sources. In addition, the water area data in this paper are from the Resource Environment Cloud Platform of the Chinese Academy of Sciences and the Earthdata database.

Table 1. Data used in the study and their sources.

\begin{tabular}{ccc}
\hline & Data Type & Source \\
\hline 1 & Water demand & the Statistical Yearbook of Jilin Province (2006-2018) \\
2 & Water available & Jilin Province long-term water supply and demand planning report \\
3 & Water conservation & Statistical Bulletin of National Economic and Social Development of \\
Jilin Province, \\
4 & Water environment & Environmental Quality Bulletin of Jilin Province, Water Resources \\
5 & Rulletin of Jilin Province \\
6 & Population and Economic & Yearbook of Jilin Water Resources Province \\
\hline
\end{tabular}

\section{Three-Stage Hybrid Model}

Based on the existing research status, this paper establishes a three-stage hybrid model integrating evaluation, prediction and regulation. It is used to analyze the WRCC in Jilin Province, and to find out the factors affecting the HWRS, in order to improve the carrying capacity of the water resources. The overall research process of this paper is shown in Figure 2. 


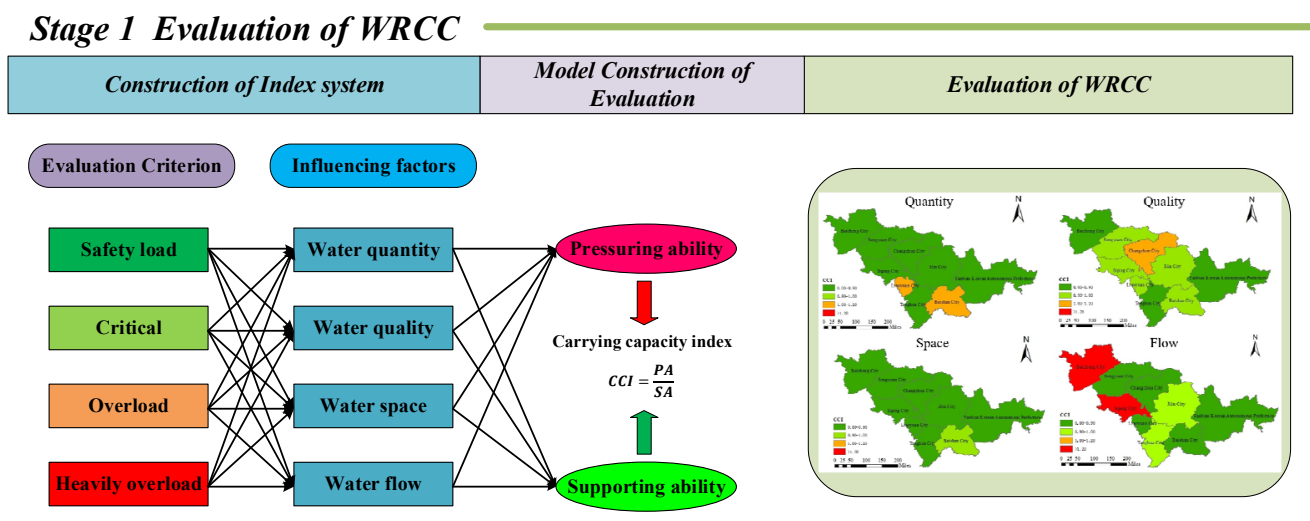

Stage 2 Prediction of WRCC

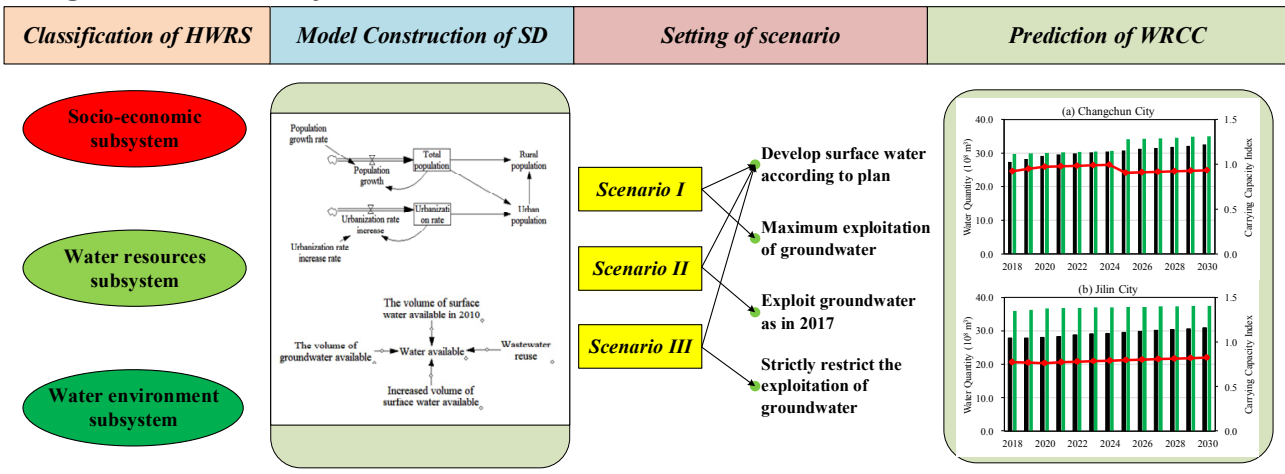

Stage 3 Regulation of WRCC

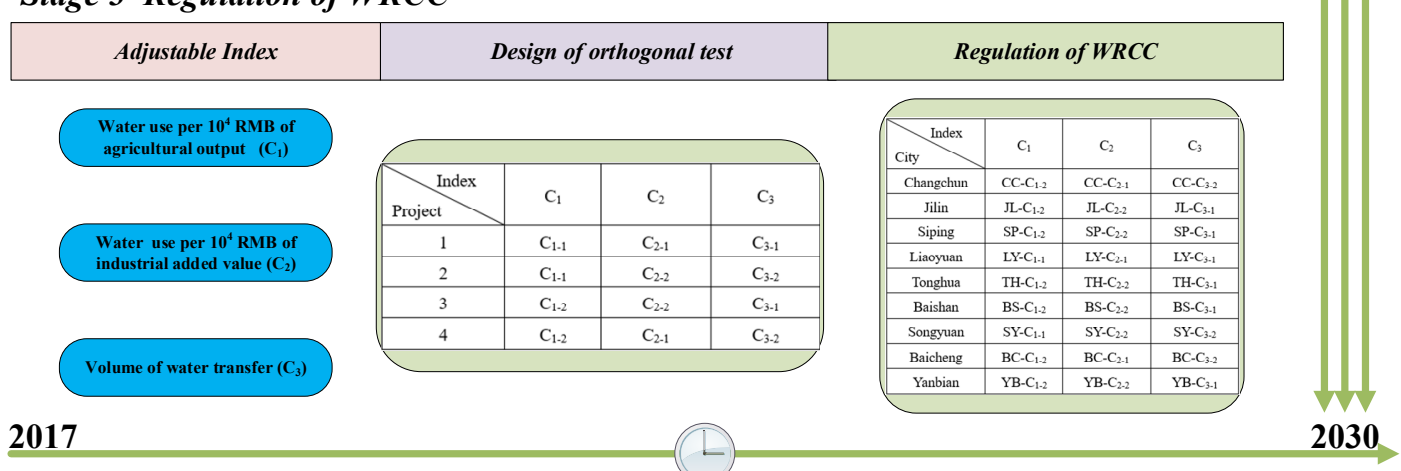

Figure 2. Framework of this work.

\subsection{Evaluation of WRCC}

\subsubsection{Evaluation System for the WRCC}

According to the system theory, the HWRS can be divided into the carrying body and the carrying object, which generate support and pressure, respectively. Between them, the carrying body is the water resources-environmental subsystem and the carrying object is the socio-economic subsystem. When the level of socio-economic activity does not exceed the threshold, the water resources-environmental subsystem can be sustainable. On the contrary, it will be damaged. It can be concluded that the accurate evaluation of the WRCC requires not only the calculation of support ability but also the calculation of pressure ability. Eventually, an evaluation system (Table 2) composed of eight indicators for the WRCC in Jilin Province was established [38]. 
Table 2. The index system for water WRCC.

\begin{tabular}{|c|c|c|c|}
\hline Factors & Variables Symbol & Indexes Name & Attributes \\
\hline \multirow{2}{*}{ Water quantity } & $P A_{1}$ & Water demand (billion $\mathrm{m}^{3}$ ) & Pressuring ability \\
\hline & $S A_{1}$ & Water available (billion $\mathrm{m}^{3}$ ) & Supporting ability \\
\hline \multirow[t]{2}{*}{ Water quality } & $P A_{2}$ & $\begin{array}{l}\text { Discharge volume of } \\
\text { pollutants (tons) }\end{array}$ & Pressuring ability \\
\hline & $S A_{2}$ & $\begin{array}{l}\text { Water environment capacity } \\
\text { (tons) }\end{array}$ & Supporting ability \\
\hline \multirow{2}{*}{ Water space } & $P A_{3}$ & Area of actual water $\left(\mathrm{km}^{2}\right)$ & Pressuring ability \\
\hline & $S A_{3}$ & Area of natural water $\left(\mathrm{km}^{2}\right)$ & Supporting ability \\
\hline \multirow{2}{*}{ Water flow } & $P A_{4}$ & Reservoir capacity (billion $\mathrm{m}^{3}$ ) & Pressuring ability \\
\hline & $S A_{4}$ & Runoff (billion $\mathrm{m}^{3}$ ) & Supporting ability \\
\hline
\end{tabular}

\subsubsection{Evaluation Model of WRCC}

As we all know, the various behaviors in the socio-economic subsystem are from human beings. Therefore, this paper uses the total population to quantitatively evaluate the WRCC. The calculation formula of carrying capacity is as follows [21]:

$$
\begin{gathered}
P_{c}=\frac{P_{t}}{C C I} \\
C C I_{i}=\frac{P A_{i}}{S A_{i}}
\end{gathered}
$$

where $P_{c}$ represents the carrying capacity at time $\mathrm{t}$, including water quantity carrying capacity, water quality carrying capacity and comprehensive carrying capacity, where the comprehensive carrying capacity is equal to the minimum of the former two. $P_{t}$ is the actual population of a region at time $t$. $C C I$ is the carrying capacity index of four factors. $P A, S A$ are pressure ability and support ability, respectively.

If the water quantity carrying capacity is bigger than the water quality carrying capacity, the limiting factor of the WRCC is water quality, which belongs to the water quality dominant area; otherwise, it belongs to the water quantity dominant area.

\subsubsection{Evaluation Criterion of WRCC}

According to the research results of the project and the opinions of relevant experts, a set of evaluation criteria was established to analyze the water resources carrying state. (i) If $C C I>1.2$, the carrying state is heavily overload; (ii) if $1.2 \geq C C I>1.0$, the carrying state is overload; (iii) if $1.0 \geq$ $C C I>0.9$, the carrying state is critical; (iv) if $0.9 \geq C C I$, the carrying state is safety load.

\subsection{Prediction of WRCC}

The system dynamics method was used to establish an SD model of WRCC, considering water resources, water environment and socio-economic. It simulates the development trend of HWRS in Jilin Province from the supply/demand of water resources, and carries out multi-scenario prediction of WRCC. The boundary of the model is the administrative boundary of Jilin Province, the time scale is 2005-2030, and the time step is 1 year. In addition, with reference to the administrative boundaries of 9 cities in Jilin Province, nine sub-models were established.

\subsubsection{Flow Diagram of SD Model}

The flow chart of the main variables in the sub-model is drawn (Figure 3). 


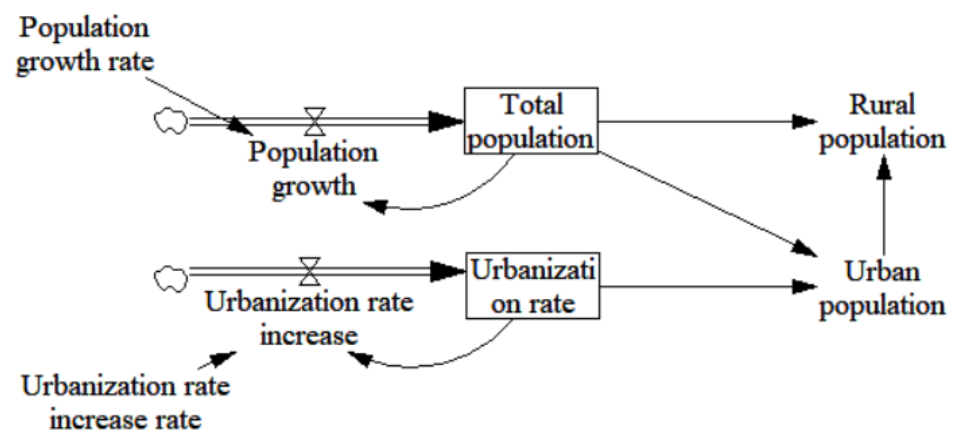

(a)

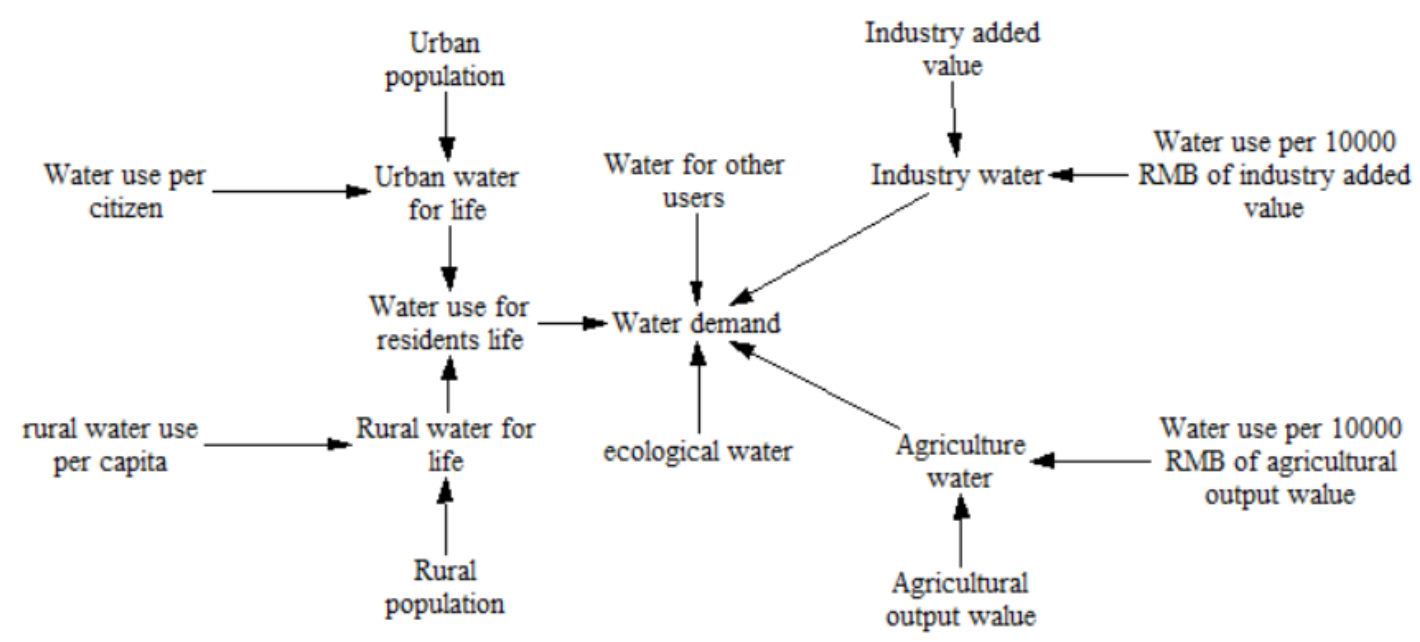

(b)

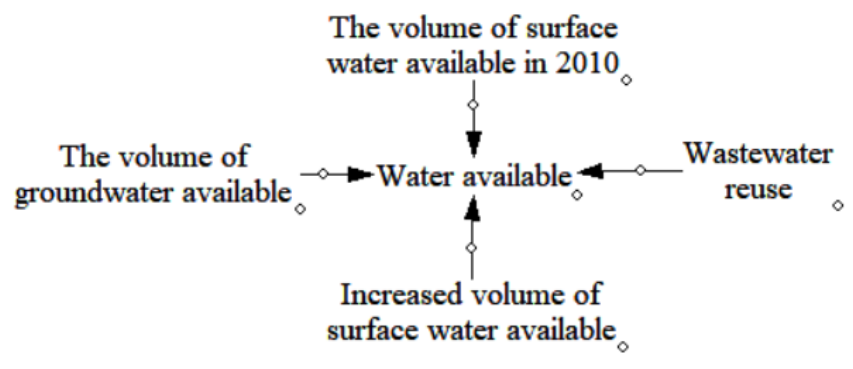

(c)

Figure 3. The flow diagram of main variables in the sub-model of WRCC: (a) total population, (b) water demand, (c) water available.

\subsubsection{Equation of SD Model}

In the SD model, mathematical equations are applied to quantify the water resources cycle. The indicators "available water quantity" and "water demand quantity" are calculated by Equations (3) and (4), respectively:

$$
\begin{gathered}
W A=W A_{t_{1}}+W A_{\Delta t} \\
W D=W D_{i w}+W D_{a w}+W D_{d w}+W D_{e w}+W D_{o w}
\end{gathered}
$$

where $W A$ represents the volume of water available. $W A_{t_{1}}$ represents the volume of water available at time $t_{1} . W A_{\Delta t}$ represents the newly added volume of water from time $t_{1}$ to time $t$. WD represents regional water demand. $W D_{i w}, W D_{a w}, W D_{e w}, W D_{o w}$ represent industrial water demand, agricultural 
water demand, ecological water demand, and other water demand, respectively. It should be mentioned that this study refers to the "Long-term Water Supply and Demand Planning of Jilin Province", and the time $t_{1}$ is set in 2010 .

\subsubsection{Scenario of HWRS}

Three scenarios were set up for the development trend of the HWRS, and the WRCC under different scenarios was predicted separately.

Scenario I: The economic development goals, irrigation construction projects, and water transfer projects planned by Jilin Province were implemented as scheduled. These contents are derived from plans such as the "13th Five-Year Plan for National Economic and Social Development" and the "Water Conservancy Modernization Plan". In addition, groundwater is mined at maximum exploitable volume.

Scenario II: The volume of groundwater exploitation is the same as in 2017 during 2018-2030. It should be mentioned that if the groundwater exploitation in 2017 exceeds the maximum exploitable volume, the groundwater extraction will be maintained at maximum exploitable volume during the forecast period.

Scenario III: According to the "Water Conservancy Modernization Plan", the proportion of groundwater in the total water supply in Jilin Province fell to $18.8 \%$ in 2030, and the total groundwater supply decreased to less than 3.5 billion $\mathrm{m}^{3}$. Therefore, in this paper, the groundwater exploitation in Changchun, Jilin, Siping, Liaoyuan, Tonghua, Baishan, Songyuan, Baicheng and Yanbian were adjusted to $60 \%, 60 \%, 70 \%, 80 \%, 60 \%, 50 \%, 70 \%, 70 \%$ and $50 \%$ of the maximum exploitable volume, respectively.

\subsection{Regulation of WRCC}

Two types of regulation were designed. The first is intra-regional regulation, that is, the regulation of the development trend of indicators in the sub-model; the second is cross-regional regulation, that is, the allocation of water resources between regions. When we design the regulation programs, we will focus on intra-regional regulation, supplemented by cross-regional regulation.

The HWRS is a complex system. The regulation of WRCC usually involves multiple variables and there are multiple adjustments to the variables, resulting in a large number of regulatory programs. The orthogonal test method is based on the probability theory, mathematical statistics and practical experience. Using the standardized orthogonal table to arrange the test plan, one can quickly find the optimization plan, which is often used to design multi-factor and multi-level optimization experiments $[39,40]$. In order to simplify the design of the scheme, the orthogonal test design method was applied to regulate the WRCC in Jilin Province.

\section{Results}

\subsection{Analysis of The WRCC in 2017}

Using the model described in the paper, the support ability, pressure ability and WRCC of Jilin was calculated. The WRCC of Jilin Province and its nine cities are described in Tables 3 and 4 and shown in Figure 4. It should be mentioned that the variables in the second line of Tables 3 and 4 are the acronyms of the names of Jilin Province. For example, "CC" is the acronym of Changchun City. 
Table 3. The carrying capacity index (CCI) of Jilin.

\begin{tabular}{ccccccccccc}
\hline \multirow{2}{*}{ CCI } & \multirow{2}{*}{ Province } & \multicolumn{7}{c}{ Prefecture-Level City and Autonomous Prefecture } \\
\cline { 3 - 11 } & & CC & JL & SP & LY & TH & BS & SY & BC & YB \\
\hline quantity & 0.76 & 0.78 & 0.64 & 0.65 & 1.05 & 0.66 & 1.16 & 0.84 & 0.85 & 0.71 \\
quality & 0.91 & 1.01 & 0.93 & 0.93 & 0.94 & 0.67 & 0.91 & 0.96 & 0.89 & 0.87 \\
domain & 0.81 & 0.68 & 0.86 & 0.72 & 0.61 & 0.64 & 0.94 & 0.87 & 0.83 & 0.82 \\
flow & 0.45 & 0.43 & 0.95 & 1.47 & 0.20 & 0.95 & 0.08 & 0.76 & 1.54 & 0.06 \\
Comprehensive & 0.91 & 1.01 & 0.93 & 0.93 & 1.05 & 0.67 & 1.16 & 0.96 & 0.89 & 0.87 \\
\hline
\end{tabular}

Table 4. The water resources carrying capacity (WRCC) of Jilin 10,000 people.

\begin{tabular}{ccccccccccc}
\hline \multirow{2}{*}{ WRCC } & \multirow{2}{*}{ Province } & \multicolumn{8}{c}{ Prefecture-Level City and Autonomous Prefecture } \\
\cline { 3 - 10 } & & CC & JL & SP & LY & TH & BS & SY & BC & YB \\
\hline Current & 2616 & 749 & 415 & 320 & 118 & 217 & 120 & 275 & 191 & 210 \\
quantity & 3496 & 965 & 645 & 492 & 112 & 329 & 103 & 330 & 224 & 295 \\
quality & 2855 & 739 & 448 & 345 & 125 & 322 & 131 & 287 & 215 & 242 \\
Comprehensive & 2855 & 739 & 448 & 345 & 112 & 322 & 103 & 287 & 215 & 242 \\
\hline
\end{tabular}

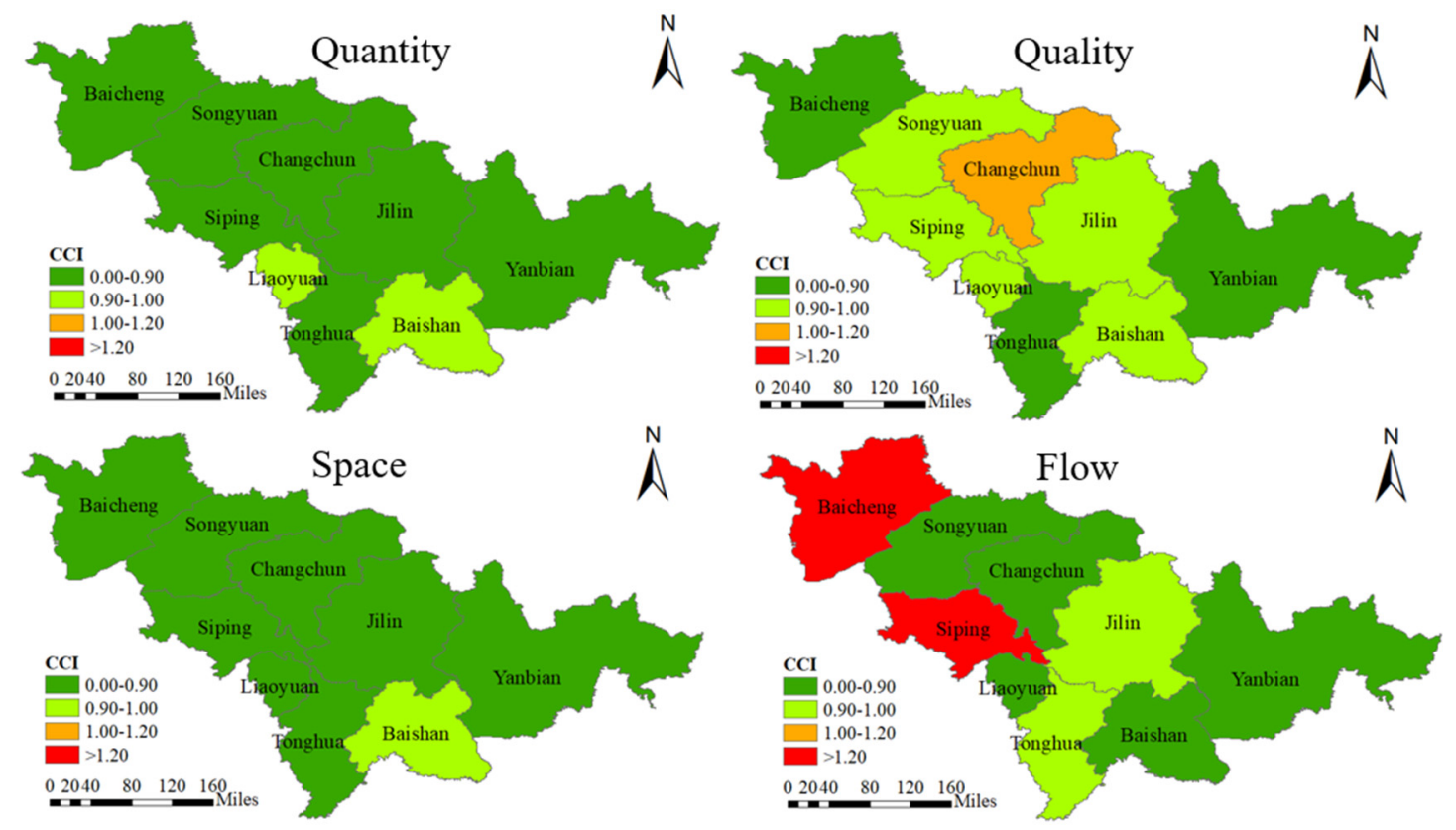

Figure 4. Carrying state of water resources.

(1) The WRCC is 28.13 million people in Jilin Province, bigger than the current population in 2017, and its comprehensive carrying capacity index (CCI) is 0.93 , which is in a critical carrying state. Among the nine cities, Changchun, Liaoyuan and Baishan have smaller comprehensive carrying capacity than the current population, and their HWRS is in an overload state. Baishan's comprehensive CCI (1.16) is the largest of all cities, followed by Liaoyuan and Changchun. The comprehensive CCI of Baishan is equal to its water quantity $\mathrm{CCI}$, which is significantly bigger than its water quality $\mathrm{CCI}$, indicating that the limiting factor of WRCC of Baishan is water quantity, which belongs to the water quantity dominant area. Baishan belongs to Changbai Mountain and has abundant water resources. However, the reservoir capacity of reservoirs is insufficient. As shown in Table 3, its water flow CCI is 0.08 . Therefore, new reservoirs can be built to increase water storage to alleviate the water shortage crisis. Liaoyuan is a water quantity dominated area and needs to increase the use of surface water. The water demand and the volume of pollutants discharged in Changchun are the largest among all cities, and its water quantity $C C I$ and water quality $C C I$ are 0.78 and 1.01 , respectively, which are the water quality 
dominant areas. As a provincial capital city, Changchun is the economic and cultural center of Jilin Province. Changchun is supposed to play a greater role in leading the industry, vigorously develop advanced manufacturing industries, and transfer some low-end industries. Furthermore, Changchun also needs to implement the principle of total pollutant control, increase investment in environmental protection. The comprehensive CCI of Jilin, Siping and Songyuan is higher than 0.9 , and its HWRS is at a critical state, and it is necessary to adhere to the red line of water resources development and utilization. Jilin city, located in the middle of Jilin province, is the transition zone between the eastern mountain area and the western plain area. It has good water resources development conditions, making its water available rank first among all cities. However, similarly to Changchun, Jilin has developed industries and emits a large amount of pollutants every year. The water environment pollution crisis still exists. There is a huge shortage of water resources in Siping and Songyuan. In order to meet the water demand in the two cities, groundwater has to be used in large quantities, causing groundwater to fall and forming a groundwater level funnel. The Central City Songhua River Water Supply Project and the Hadashan Water Conservancy Project were constructed to alleviate the water crisis in Changchun, Siping, Liaoyuan and Songyuan. The comprehensive CCI of Tonghua, Baicheng and Yanbian are all below 0.9, and the HWRS is in a safe carrying state. The water quantity CCI of these three cities is higher than the water quality $C C I$ and they belong to the water quality dominant areas. Therefore, while developing the economy in the future, they should always pay attention to environmental protection.

(2) The water quantity carrying state of Jilin Province is generally good. Except for the fact that Baishan and Liaoyuan are in an overload state, the remaining cities are in a safe carrying state. Among them, the reasons for the overload of Baishan and Liaoyuan are different. The main reason for the Baishan overload is the lack of water conservancy engineering facilities. The main reason for the Liaoyuan overload is the shortage of water resources. The water quality carrying state of Jilin Province is expected to gradually deteriorate from the periphery to the center. For example, the water quality CCI of Changchun and Jilin ranks first and third among all the cities. The water space carrying states of all cities are in good condition. Except for the fact that Baishan is in a critical state, the other eight cities are safely loaded. It can be concluded that each city has enough space to accommodate water resources. In terms of water mobility, the water flow carrying states of Baicheng and Siping are heavily overloaded, and the remaining seven cities are not. Baicheng is located in the western part of Jilin Province. The water resources are extremely scarce. A large amount of water needs to be stored to meet the demand for water. As a result, the area of wetlands and lakes in the territory is shrinking. As an ecological barrier zone in the west, Baicheng needs to improve its water use efficiency on the one hand and increase its water transfer from other regions on the other hand. The project to transfer water resources of Nenjiang into Baicheng was built to increase the volume of water available, and alleviate the crisis of ecological water shortage.

\subsection{Future Simulation of the WRCC}

\subsubsection{Model Validation}

Taking Jilin Province and Changchun City as examples, this model was used to estimate the values of major variables such as population, GDP, industrial water, and water demand in 2005-2017. The relative errors of these variables are shown in Table 5 . The relative errors of the main variables in Jilin Province and Changchun City are small, and the maximum value is $2.44 \%$. The SD model established in this study performed well and can be used for further analysis. 
Table 5. Relative errors of the main variables between simulated data and historic data.

\begin{tabular}{ccccccccc}
\hline \multirow{2}{*}{ Year } & \multicolumn{3}{c}{ Jilin Province } & \multicolumn{4}{c}{ Changchun City } \\
\cline { 2 - 9 } & Population & GDP & $\begin{array}{c}\text { Industry } \\
\text { Water }\end{array}$ & $\begin{array}{c}\text { Water } \\
\text { Demand }\end{array}$ & Population & GDP & $\begin{array}{c}\text { Industry } \\
\text { Water }\end{array}$ & $\begin{array}{c}\text { Water } \\
\text { Demand }\end{array}$ \\
\hline 2005 & 0 & 0 & $0.48 \%$ & $-1.45 \%$ & 0 & 0 & $0.43 \%$ & $0.58 \%$ \\
2006 & 0 & 0 & $0.05 \%$ & $0.17 \%$ & 0 & 0 & $1.25 \%$ & $0.51 \%$ \\
2007 & 0 & 0 & $-0.10 \%$ & $0.04 \%$ & 0 & 0 & $0.80 \%$ & 0 \\
2008 & 0 & 0 & 0 & 0 & 0 & 0 & $0.40 \%$ & $0.05 \%$ \\
2009 & 0 & 0 & 0 & 0 & 0 & 0 & $0.84 \%$ & $0.10 \%$ \\
2010 & 0 & 0 & 0 & 0 & 0 & 0 & $-0.28 \%$ & $0.12 \%$ \\
2011 & 0 & 0 & 0 & 0 & 0 & 0 & $0.28 \%$ & $0.09 \%$ \\
2012 & 0 & 0 & 0 & 0 & 0 & 0 & $0.24 \%$ & $0.08 \%$ \\
2013 & 0 & 0 & 0 & 0 & 0 & 0 & $0.48 \%$ & $0.08 \%$ \\
2014 & 0 & 0 & 0 & 0 & 0 & 0 & $2.44 \%$ & $0.04 \%$ \\
2015 & 0 & 0 & $2.41 \%$ & $1.29 \%$ & 0 & 0 & $0.28 \%$ & $-0.13 \%$ \\
2016 & 0 & 0 & $0.47 \%$ & $0.14 \%$ & 0 & 0 & $0.35 \%$ & $0.07 \%$ \\
2017 & 0 & 0 & $0.06 \%$ & $0.03 \%$ & 0 & 0 & $0.51 \%$ & $0.16 \%$ \\
\hline
\end{tabular}

\subsubsection{Provincial Simulation}

Table 6 shows the simulation results of water demand/available in Jilin Province. As shown in Table 6, with the continuous development of the economy, the total water demand in Jilin Province increased year by year, but the growth rate slowed down. We predict that water demand in Jilin Province will reach 15.35 billion $\mathrm{m}^{3}$ in 2020 and 17.05 billion $\mathrm{m}^{3}$ in 2030. With the advancement of agricultural modernization and water conservancy modernization, Jilin Province will expand the area of agricultural planting, which will focus on expanding its rice planting area and its agricultural water consumption will also increase. We predict that it will exceed 11.5 billion $\mathrm{m}^{3}$ in 2030 . The total volume of industrial water is closely related to the total industrial added value and industrial water efficiency. It will increase slightly with the revitalization of industrial bases. We predict that it will reach 2.42 billion $\mathrm{m}^{3}$ in 2020 and 2.85 billion $\mathrm{m}^{3}$ in 2030 . The living standards of the people are constantly improving. We assume that the per capita domestic water demand in urban areas and the per

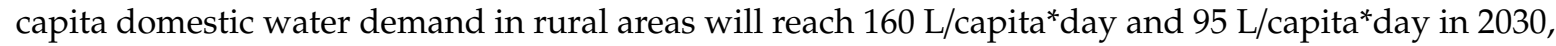
respectively. We predict that the total domestic water demand will reach 2.19 billion $\mathrm{m}^{3}$. The water resources in the east are abundant, and the volume of ecological water is small. The ecological water demand will increase in the west, which will ensure the sustainable development of the ecosystem. We predict that it will reach 480 million $\mathrm{m}^{3}$ in 2030.

Table 6. Simulation results of water demand/available in Jilin Province from 2018 to 2030.

\begin{tabular}{|c|c|c|c|c|c|c|c|c|c|c|c|}
\hline \multirow{3}{*}{ Year } & \multicolumn{5}{|c|}{ Water Demand $/ 10^{9} \mathrm{~m}^{3}$} & \multirow{2}{*}{\multicolumn{3}{|c|}{$\begin{array}{c}\text { Water Available } / 10^{9} \mathrm{~m}^{3} \\
\text { Scenario }\end{array}$}} & \multirow{2}{*}{\multicolumn{3}{|c|}{$\frac{\text { CCI }}{\text { Scenario }}$}} \\
\hline & \multirow{2}{*}{ Total } & \multirow{2}{*}{ Agriculture } & \multirow{2}{*}{ Industry } & \multirow{2}{*}{ Domestic } & \multirow{2}{*}{ Ecological } & & & & & & \\
\hline & & & & & & I & II & III & I & II & III \\
\hline 2018 & 145.4 & 101.6 & 24.4 & 15.2 & 4.2 & 168.8 & 160.5 & 151.1 & 0.86 & 0.91 & 0.96 \\
\hline 2019 & 149.5 & 105.0 & 24.3 & 16.0 & 4.2 & 171.1 & 162.8 & 153.4 & 0.87 & 0.92 & 0.97 \\
\hline 2020 & 153.2 & 108.1 & 24.2 & 16.8 & 4.1 & 182.3 & 174.0 & 164.6 & 0.84 & 0.88 & 0.93 \\
\hline 2021 & 155.2 & 109.1 & 24.7 & 17.3 & 4.2 & 183.3 & 174.9 & 165.6 & 0.85 & 0.89 & 0.94 \\
\hline 2022 & 157.2 & 110.0 & 25.1 & 17.8 & 4.2 & 189.4 & 181.1 & 171.7 & 0.83 & 0.87 & 0.92 \\
\hline 2023 & 159.2 & 111.0 & 25.5 & 18.3 & 4.3 & 190.3 & 182.0 & 172.6 & 0.84 & 0.87 & 0.92 \\
\hline 2024 & 161.2 & 112.0 & 25.9 & 18.9 & 4.3 & 192.1 & 183.8 & 174.4 & 0.84 & 0.88 & 0.92 \\
\hline 2025 & 163.1 & 113.0 & 26.3 & 19.4 & 4.4 & 200.0 & 191.7 & 182.4 & 0.82 & 0.85 & 0.89 \\
\hline 2026 & 164.7 & 113.5 & 26.8 & 19.9 & 4.4 & 200.5 & 192.1 & 182.8 & 0.82 & 0.86 & 0.90 \\
\hline 2027 & 166.2 & 114.0 & 27.3 & 20.4 & 4.5 & 200.9 & 192.5 & 183.2 & 0.83 & 0.86 & 0.91 \\
\hline 2028 & 167.7 & 114.4 & 27.8 & 20.9 & 4.5 & 201.3 & 193.0 & 183.6 & 0.83 & 0.87 & 0.91 \\
\hline 2029 & 169.1 & 114.9 & 28.2 & 21.4 & 4.6 & 201.7 & 193.4 & 184.0 & 0.84 & 0.87 & 0.92 \\
\hline 2030 & 170.5 & 115.4 & 28.5 & 21.9 & 4.6 & 202.1 & 193.8 & 184.5 & 0.84 & 0.88 & 0.92 \\
\hline
\end{tabular}


The volume of water available is different in three scenarios in Jilin Province. Scenario I maximizes the development of groundwater, resulting in the largest volume of water available in Jilin Province. We predict it will reach 18.23 billion $\mathrm{m}^{3}$ in 2020 and 20.21 billion $\mathrm{m}^{3}$ in 2030. Groundwater development in Scenario II is the same as in 2017, making groundwater supply less than the maximum developable amount, so the increase in water available will depend on surface water and reclaimed water. We predict that the water available will reach 17.4 billion $\mathrm{m}^{3}$ in 2020 and 19.38 billion $\mathrm{m}^{3}$ in 2030. Scenario III controls the groundwater development strictly and reduces the proportion of groundwater supply, which will increase the volume of groundwater in the emergency reserve water source and return the over-exploited groundwater in history. We predict that the water available will reach 16.46 billion $\mathrm{m}^{3}$ in 2020 and 18.4 billion $\mathrm{m}^{3}$ in 2030.

The water quantity CCI of Jilin Province has not exceeded one in three scenarios from 2018 to 2030. This shows that if Jilin Province can complete the modernization of water conservancy on schedule and transfer the water from the east to the west, the available water can generally meet the demand for water. In addition, the water quantity CCI in scenario III is the highest of all the scenarios during the same period. Groundwater development is strictly controlled, which is bound to reduce the volume of water available but it is still bigger than the water demand, indicating that scenario III is feasible.

It should be mentioned that the spatial distribution of water resources in Jilin Province is extremely uneven, so it is necessary to predict and analyze the water quantity carrying states of each city in scenario III.

\subsubsection{City Simulation}

Figure 5 shows the forecast results of water demand/available in all cities of Jilin Province from 2018 to 2030. As shown in Figure 5, the water demand of Changchun and Jilin is more than 2.5 billion $\mathrm{m}^{3}$ during the forecast period and exceeds 3 billion $\mathrm{m}^{3}$ in the 14th and 15th "five-year plans", respectively. Their GDP is located in the top two in Jilin Province, and the demand for water resources is enormous. However, there is a large gap in the volume of water available between the two cities. The volume of water resources in Jilin is significantly bigger than that in Changchun, which can fully meet the water demand. The water quantity CCI of Changchun exceeds 0.9 every year, and there is a risk of water shortage. It is necessary to improve the utilization rate of water resources. The water resources in Siping and Liaoyuan are extremely short, and it is urgent to transfer water across regions. We assume that The Central City Songhua River Water Supply Project will be completed in 2020. The water availability of the two cities will increase significantly and the water crisis will be basically solved. The water quantity CCI will decreased to 0.9 and 0.8 .

Among the three cities in the east, Baishan is the main one engaged in the development of green economy, and its water resources development is low. Its water demand is close to that of Liaoyuan, ranking last in all cities. We predict that it will reach 0.33 billion $\mathrm{m}^{3}$ in 2020 and 0.37 billion $\mathrm{m}^{3}$ in 2030 . Due to the insufficient water storage capacity of the water conservancy project, Baishan is unable to meet the water demand before 2024. During the 15th five-year plan period, after the completion of the proposed water conservancy project in Baishan, it will return to the safe carrying state, and the water crisis will be basically solved. Yanbian is located in the Chang-Ji-Tu Economic Zone and has a large demand for water. We predict it will reach 1.20 billion $\mathrm{m}^{3}$ in 2020 and 1.25 billion $\mathrm{m}^{3}$ in 2030 . Several water storage projects and water transfer projects were planned in 2018-2030. Assuming that these projects are completed on schedule, we predict that the volume of water available for Yanbian will increase to 1.49 billion $\mathrm{m}^{3}$ in 2020 and 1.57 billion $\mathrm{m}^{3}$ in 2030, and its water quantity CCI will decrease to 0.81 and 0.79 , respectively. The water demand of Tonghua is the highest among the three cities. We predict that it will reach 1.6 billion $\mathrm{m}^{3}$ in 2020 and 1.68 billion $\mathrm{m}^{3}$ in 2030 . The degree of water resources development is significantly higher in Tonghua than in the other two cities, but the volume of water available of Tonghua is still lower than its water demand. Therefore, Tonghua needs to increase water conservation efforts. 

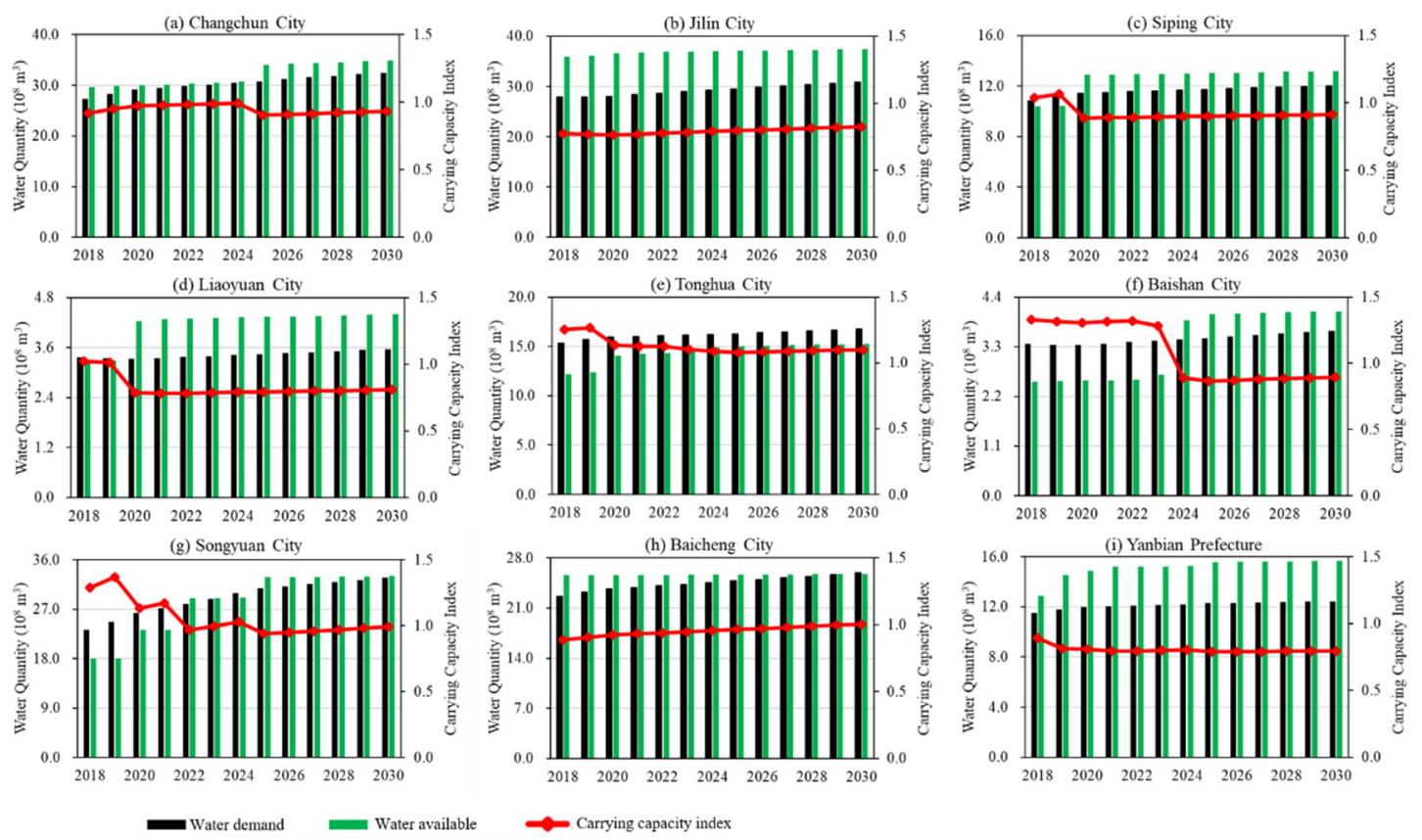

Figure 5. Simulation results of water demand/available in nine cities from 2018 to 2030.

Baicheng and Songyuan are located in the west and their water resources are extremely scarce. Due to fertile land resources, they are the most important agricultural bases in Jilin Province and even China. Their agricultural water use accounts for more than $80 \%$. According to the plan, the area of newly built and expanded irrigation districts will exceed 3.5 million mu in Songyuan, resulting in an increase in the agricultural water demand. We predict that the water demand in Songyuan will reach 2.63 billion $\mathrm{m}^{3}$ in 2020 and 3.27 billion $\mathrm{m}^{3}$ in 2030. More than 2 million mu of irrigation districts are planned to be built in Baicheng. In order to meet the demand for water, the Hadashan Water Conservancy Project and the water diversion Project from Nenjiang river to Baicheng were constructed. They were used to transfer the water from the Songhua River and Nenjiang River to the two cities. The water shortage will be compensated, if the two projects meet the target in the two cities.

According to the above analysis, it can be found that the uneven distribution of water resources in Jilin Province will be alleviated by water saving and inter-regional water transfer. However, there is still a city with a water quantity CCI bigger than 1 , so it is necessary to regulate the HWRS in Jilin Province.

\subsection{Analysis of the Regulation Program and Results}

\subsubsection{Analysis of Regulatory Indicators}

Based on the prediction results in Section 5.2, the three major water users in Jilin Province are agriculture, industry and domestic. Agricultural water use is closely related to agricultural output value and water use per 10,000 RMB of agricultural output value $\left(C_{1}\right)$. Regulation of $C_{1}$ will directly affect the total volume of agricultural water. Industrial water is also the main target of regulation. Its value is determined by the industrial added value and the water use per 10,000 RMB of industrial added value $\left(\mathrm{C}_{2}\right)$. The modernization of agriculture and industry currently being implemented in Jilin Province will inevitably lead to an increase in agricultural output value and industrial added value. Therefore, it is crucial to control the water use by regulating $C_{1}$ and $C_{2}$. At present, the per capita domestic water use in Jilin Province is less than the average level in China. Scenario III has raised it to the average level, so this section will not regulate it. Furthermore, the forecast results show that some cities have not been able to meet their water demand after water transfer from other regions. Based on the above analysis, the variables will be used for the adjustment program of the next section, 
including the water use per $10,000 \mathrm{RMB}$ of agricultural output value $\left(\mathrm{C}_{1}\right)$, the water use per 10,000 RMB of industrial added value $\left(C_{2}\right)$ and the volume of water transfer $\left(C_{3}\right)$.

\subsubsection{Analysis of Regulatory Program}

According to the national and local planning, two regulatory values were set for $\mathrm{C} 1, \mathrm{C} 2$ and $\mathrm{C} 3$, respectively. The most suitable regulatory project was selected through orthogonal tests. Based on the historical value of 2015, the adjusted value of this parameter is obtained in 2030. The value of 0.9 was chosen as the limit of the water quantity CCI in this section, that is, the HWRS reached a safe load state. The recommended projects for each city are described in Table 7.

Table 7. Regulation program of WRCC.

\begin{tabular}{|c|c|c|c|c|c|c|c|}
\hline City & $\begin{array}{c}\mathrm{C}_{1} \mathrm{~m}^{3} / 10^{4} \\
\mathrm{RMB}\end{array}$ & $\begin{array}{c}\mathrm{C}_{2} \mathrm{~m}^{3} / \mathbf{1 0}^{4} \\
\mathrm{RMB}\end{array}$ & $C_{3} 10^{8} \mathrm{~m}^{3}$ & City & $\begin{array}{c}\mathrm{C}_{1} \mathrm{~m}^{3} / 10^{4} \\
\mathrm{RMB}\end{array}$ & $\begin{array}{c}\mathrm{C}_{2} \mathrm{~m}^{3} / 10^{4} \\
\mathrm{RMB}\end{array}$ & $C_{3} 10^{8} \mathrm{~m}^{3}$ \\
\hline Changchun & $+10 \%$ & $-45 \%$ & 11 & Baishan & $+10 \%$ & $-45 \%$ & 0 \\
\hline Jilin & $+12 \%$ & $-35 \%$ & 0 & Songyuan & $+25 \%$ & $-45 \%$ & 15 \\
\hline Siping & $+17 \%$ & $-45 \%$ & 2.6 & Baicheng & $+14 \%$ & $-40 \%$ & 12 \\
\hline Liaoyuan & 0 & $-40 \%$ & 0.7 & Yanbian & $+5 \%$ & $-40 \%$ & 0 \\
\hline Tonghua & $-5 \%$ & $-45 \%$ & 4 & & & & \\
\hline
\end{tabular}

The water allocation data of Jilin Province (Table 8) was obtained, which regulates the HWRS according to the program shown in Table 7 . The variables in Table 8 are composed of surface water (SW), ground water (GW), transfer water (TW), reclaimed water (RW), agriculture water (AW), industry water (IW), domestic water (DW), and ecological water (EW). The volume of water available in Jilin Province is 18.85 billion $\mathrm{m}^{3}$, the water demand is 16.68 billion $\mathrm{m}^{3}$, and the water quantity CCI is 0.88 , which is in a safe load state in 2030. This shows that the above regulation program is feasible. Fortunately, water conservancy modernization is currently being implemented in Jilin Province, which will increase the volume of water available in the central and western regions. In addition, the upgrading of industrial structure is underway, which is expected to reduce the water use per 10,000 RMB of industrial added value.

Table 8. Water allocation results of Jilin province in 2030.

\begin{tabular}{|c|c|c|c|c|c|c|c|c|c|c|c|}
\hline \multirow{2}{*}{ Region } & \multicolumn{5}{|c|}{ Water Available $/ 10^{8} \mathrm{~m}^{3}$} & \multicolumn{5}{|c|}{ Water Demand $/ 10^{8} \mathrm{~m}^{3}$} & \multirow{2}{*}{$C C I$} \\
\hline & SW & GW & TW & RW & Total & AW & IW & DW & EW & Total & \\
\hline $\mathrm{CC}$ & 14.78 & 6.75 & 11 & 4.16 & 36.69 & 19.22 & 4.52 & 8 & 1.3 & 33.04 & 0.90 \\
\hline $\mathrm{JL}$ & 29.85 & 3.66 & 0 & 3.73 & 37.24 & 14.37 & 13.59 & 4.03 & 1.1 & 33.09 & 0.89 \\
\hline SP & 4.98 & 4.83 & 2.6 & 0.94 & 13.35 & 8.32 & 1.69 & 1.63 & 0.37 & 12.01 & 0.90 \\
\hline $\mathrm{LY}$ & 2.03 & 0.99 & 0.7 & 0.41 & 4.13 & 1.75 & 1.07 & 0.55 & 0.3 & 3.67 & 0.89 \\
\hline $\mathrm{TH}$ & 10.97 & 0.84 & 4 & 1.81 & 17.62 & 9.85 & 3.4 & 1.85 & 0.19 & 15.29 & 0.87 \\
\hline BS & 3.35 & 0.44 & 0 & 0.39 & 4.18 & 0.58 & 1.73 & 1.12 & 0.23 & 3.66 & 0.88 \\
\hline SY & 10.89 & 6.6 & 15 & 1.05 & 33.54 & 25.78 & 2.25 & 1.81 & 0.38 & 30.22 & 0.90 \\
\hline BC & 5.96 & 7.93 & 12 & 0.54 & 26.43 & 21.53 & 0.79 & 1.01 & 0.24 & 23.57 & 0.89 \\
\hline $\mathrm{YB}$ & 12.94 & 1.19 & 0 & 1.21 & 15.34 & 8.92 & 1.14 & 1.93 & 0.26 & 12.25 & 0.80 \\
\hline Total & 95.74 & 33.23 & 45.30 & 14.24 & 188.51 & 110.32 & 30.18 & 21.93 & 4.37 & 166.80 & 0.88 \\
\hline
\end{tabular}

\section{Discussion}

A three-stage hybrid model, including evaluation, prediction, and regulation, is established in this paper. It was used to analyze the WRCC of Jilin Province. According to the evaluation results in Section 5.1, the water resources problems faced by cities in Jilin Province in 2017 are different and there is inconsistency between the socio-economic subsystem and the water resources-environmental subsystem. For example, in order to meet the demand for water, surface water and groundwater have been extensively developed in Baicheng and Siping, causing their water flow factor to be overloaded. 
Due to the lack of water conservancy facilities, Baishan has less interference with rivers than the previous two cities, so that its water flow factor is in a safe load state, but the water quantity factor is in an overload state. The evaluation results of the above three cities indicate that there are advantages and disadvantages in reservoir construction. The advantage is that water can be stored to meet the demand for water. The disadvantage is that it destroys the fluidity of the water and causes damage the aquatic ecosystem [41,42].

According to the dynamic forecast of WRCC in Section 5.2, if the water transfer and water storage projects in the Water Conservancy Modernization Plan are completed on schedule, the volume of water resources transferred from the east to the central and western regions will increase, which can effectively alleviate the shortage of water resources in these regions. Groundwater resources are also protected. In addition, this study analyzes the impact of water conservancy engineering facilities on the water resources system of Jilin Province in the relevant plans, as shown in Table 9. After the modernization of water conservancy, the surface water in Changchun, Siping, Baicheng and Songyuan will increase significantly. In addition, the surface water of Baishan and Yanbian in the east also increased. This indicates that after the completion of the construction of the water conservancy project, it will not only transport surface water for the central and western regions, but also not cause surface water reduction in the eastern region. Water modernization construction will bring inestimable economic and ecological benefits to Jilin Province.

Table 9. The change in surface water available.

\begin{tabular}{cccccccccc}
\hline Year & CC & JL & SP & LY & TH & BS & SY & BC & YB \\
\hline 2017 & 14.78 & 29.85 & 4.98 & 2.03 & 9.99 & 1.83 & 10.89 & 12.8 & 10.91 \\
2030 & 24.02 & 30.08 & 7.40 & 3.00 & 12.61 & 3.25 & 25.38 & 17.31 & 13.94 \\
\hline
\end{tabular}

Combined with the regulation analysis of Section 5.3, the indicators need to be adjusted simultaneously, including the water use per 10,000 RMB of agricultural output, the water use per 10,000 RMB of industrial added value and the volume of water transfer, which will balance the water demand/available from 2018 to 2030. The water use efficiency of agriculture and industry will change through the regulation of the first two indicators. It can be concluded that the regulation of WRCC not only needs to strengthen water conservation, but also needs to rationally dispatch water resources by breaking the boundary of the region, which can solve the problem of water imbalance between regions. China's South-to-North Water Transfer Project is a successful case [43].

There is a plan in Jilin Province called "Main Pollutant Total Emission Reduction Plan", which sets the total control target for various pollutants. Referring to the plan, the value of the indicator "water environment capacity" is obtained. With the increasingly strict enforcement of environmental protection, all cities will strictly abide by the pollutant emission reduction plan, which is mandatory. We predict that there will be no more overloading of the water quality factor. In addition, it should be mentioned that the evaluation result of the carrying state of the water space has limitations. It can only reflect the ratio of the water area to the basin area, which is greatly affected by the water volume in the current year. In summary, this paper carries out the assessment of WRCC from four factors: water quantity, water quality, water space and water flow. It differs from previous studies that focused on the first two factors. Compared with the existing research, the SD model of this paper couples the city-scale models of each city into a provincial-scale model by connecting key indicators. It can simulate and analyze WRCC at different scales, which is complex and advanced. Furthermore, the results of water allocation are obtained in this paper, which will provide reference for water resources management in Jilin Province.

\section{Conclusions}

According to the characteristics of HWRS in Jilin Province, the load-balance method was used to establish an indexes system consisting of four factors and eight indicators. Then, the SD method was 
applied to construct a model that includes socio-economic, water resources, and water environment. Through the validity test, it is verified that the SD model can the simulate the HWRS of Jilin Province. Three scenarios were set up to simulate the dynamic trend of WRCC. Using the simulation results of the all three scenarios, an orthogonal test method was adopted to select the best project. Finally, the results of water resources allocation in 2030 were obtained in Jilin Province. The current analysis allows us to draw the following conclusions.

(1) The evaluation results of WRCC indicate that the HWRS of Changchun, Liaoyuan and Baicheng are overloaded. The pressure of socio-economic activities exceeded the support of water resources-environmental in these cities. The HWRS of Jilin, Siping and Songyuan are in a critical state, very close to the warning line. The WRCC of other cities is surplus.

(2) The total water demand in Jilin Province continued to increase from 2018 to 2030. We predict that it will reach 15.35 billion $\mathrm{m}^{3}$ in 2020 and 17.05 billion $\mathrm{m}^{3}$ in 2030 . The water available of the three scenarios can meet the future water demand. Among them, Scenario III imposes the most restrictive restrictions on groundwater development, resulting in the closest water quantity CCI to the warning line, but it is still feasible. Among the nine cities, Siping, Tonghua, Baishan, Songyuan and Baicheng will experience water shortages and the rest will not.

(3) In order to realize the sustainable development of the HWRS, Jilin Province needs to strictly control the growth rate of agricultural water consumption, improve the efficiency of industrial water use, and strengthen the cross-regional distribution of water resources.

The three-stage hybrid model proposed in this paper is reasonable for studying the WRCC and has application value for water resources management.

Author Contributions: Conceptualization, T.L. and X.Y.; methodology, T.L., B.S.; software, T.L., B.S.; validation, T.L.; formal analysis, X.Y.; investigation, T.L.; resources, X.Y.; data curation, T.L., L.G.; writing-original draft preparation, T.L.; writing-review and editing, X.Y.; visualization, X.Y.; supervision, X.Y.; project administration, X.Y.; funding acquisition, X.Y., L.G. All authors have read and agreed to the published version of the manuscript.

Funding: This work was supported by the National Key Research Program of China (No. 2016YFC0401305, No. 2017YFC0506603), the State Key Program of National Natural Science of China (No. 41530635), and the Project of National Natural Foundation of China (No. 51679007, 51379013).

Acknowledgments: Thanks to reviewers and editors for their valuable suggestions.

Conflicts of Interest: The authors declare no conflict of interest.

\section{References}

1. Chen, Y.L.; Wang, S.S.; Ren, Z.G.; Huang, J.F.; Wang, X.Z.; Liu, S.S.; Deng, H.J.; Lin, W.K. Increased evapotranspiration from land cover changes intensified water crisis in an arid river basin in north China. J. Hydrol. 2017, 574, 383-397. [CrossRef]

2. Beck, L.; Bernauer, L. How will combined changes in water demand and climate affect water availability in the Zambezi river basin. Glob. Environ. Chang. 2011, 21, 1061-1072. [CrossRef]

3. Chen, B.; Wang, M.; Duan, M.X.; Ma, X.T.; Hong, J.L.; Xie, F.; Zahng, R.R.; Li, X.Z. In search of key: Protecting human health and the ecosystem from water pollution in China. J. Clean. Prod. 2019, 228, 101-111. [CrossRef]

4. Gleick, P.H.; Palaniappan, M. Peak water limits to freshwater withdrawal and use. Proc. Natl. Acad. Sci. USA 2010, 107, 11155-11162. [CrossRef]

5. Wang, Y.Z.; Liu, L.; Guo, S.S.; Yue, Q.; Guo, P. A bi-level multi-objective linear fractional programming for water consumption structure optimization based on water shortage risk. J. Clean. Prod. 2019, 237, 117829. [CrossRef]

6. Wang, H.; Asefa, T.; Bracciano, D.; Adams, A.; Wanakule, N. Proactive water shortage mitigation integrating system optimization and input uncertainty. J. Hydrol. 2019, 571, 711-722. [CrossRef]

7. Yan, R.H.; Gao, Y.N.; Li, L.L.; Gao, J.F. Estimation of water environmental capacity and pollution load reduction for urban lakeside of Lake Taihu, eastern China. Ecol. Eng. 2019, 139, 105587. [CrossRef]

8. Wang, Q.R.; Liu, R.M.; Men, C.; Guo, L.J.; Miao, Y.X. Temporal-spatial analysis of water environmental capacity based on the couple of SWAT model and differential evolution algorithm. J. Hydrol. 2019, 569, 155-166. [CrossRef] 
9. Wen, Z.G.; Meng, F.X.; Di, J.H.; Tan, Q.L. Technological approaches and policy analysis of integrated water pollution prevention and control for the coal-to-methanol industry based on Best Available Technology. J. Clean. Prod. 2016, 113, 231-240. [CrossRef]

10. Manzano-Solís, L.R.; Díaz-Delgado, C.; Gómez-Albores, M.A.; Mastachi-Loza, C.A.; Soares, D. Use of structural systems analysis for the integrated water resources management in the Nenetzingo river watershed, Mexico. Land Use Policy 2019, 87, 104029. [CrossRef]

11. Wang, K.; Davies, E.G.R.; Liu, J.G. Integrated water resources management and modeling: A case study of Bow river basin, Canada. J. Clean. Prod. 2019, 240, 118242. [CrossRef]

12. Arrow, K.; Bolin, B.; Costanza, R.; Dasgupta, P.; Folke, C.; Holling, C.S.; Jansson, B.O.; Levin, S.; Mäler, K.G.; Perrings, C.; et al. Economic growth, carrying capacity, and the environment. Ecol. Econ. 1995, 15, 91-95. [CrossRef]

13. Peng, B.H.; Li, Y.; Elahi, E.; Wei, G. Dynamic evolution of ecological carrying capacity based on the ecological footprint theory: A case study of Jiangsu province. Ecol. Indic. 2019, 99, 19-26. [CrossRef]

14. Li, C.; Li, H.J.; Feng, S.D.; Liu, X.Y.; Guo, S. A study on the spatiotemporal characteristics and change trend of the atmospheric environmental carrying capacity in the Jing-Jin-Ji region, China. J. Clean. Prod. 2019, 211, 27-35. [CrossRef]

15. Shi, Y.S.; Wang, H.F.; Yin, C.Y. Evaluation method of urban land population carrying capacity based on GIS-A case of Shanghai, China. Comput. Environ. Urban. Syst. 2013, 39, 27-38. [CrossRef]

16. Wang, D.L.; Shi, Y.H.; Wan, K.D. Integrated evaluation of the carrying capacities of mineral resource-based cities considering synergy between subsystems. Ecol. Indic. 2020, 108, 105701. [CrossRef]

17. Zeng, W.H.; Cheng, S.T. Preliminary suggestion on integrated planning of aquatic environment. Shuili Xuebao 1997, 10, 77-82. (In Chinese)

18. Falkenmark, M.; Lundqvst, J. Towards water security: Political determination and human adaptation crucial. Nat. Resour. Forum 1998, 21, 37-51. [CrossRef]

19. Yang, J.F.; Lei, K.; Khu, S.; Meng, W. Assessment of Water Resources Carrying Capacity for Sustainable Development Based on a System Dynamics Model: A Case Study of Tieling City, China. Water Resour. Manag. 2015, 29, 885-899. [CrossRef]

20. Wang, Z.G.; Luo, Y.Z.; Zhang, M.H.; Xia, J. Quantitative Evaluation of Sustainable Development and Eco-Environmental Carrying Capacity in Water-Deficient Regions: A Case Study in the Haihe River Basin, China. J. Integr. Agric. 2014, 13, 195-206. [CrossRef]

21. Wang, J.H.; Zhai, Z.L.; Sang, X.F.; Li, H.H. Study on index system and judgment criterion of water resources carrying capacity. Shuili Xuebao 2017, 48, 1023-1029. (In Chinese)

22. Munyaneza, C.; Kurwijila, L.R.; Mdoe, N.S.Y.; Baltenweck, I.; Twine, E.E. Identification of appropriate indicators for assessing sustainability of small-holder milk production systems in Tanzania. Sustain. Prod. Consum. 2019, 19, 141-160.

23. Lin, T.; Ge, R.B.; Huang, J.; Zhao, Q.J.; Lin, J.Y.; Huang, N.; Zhang, G.Q.; Li, X.H.; Ye, H.; Yin, K. A quantitative method to assess the ecological indicator system's effectiveness: A case study of the Ecological Province Construction Indicators of China. Ecol. Indic. 2016, 62, 95-100. [CrossRef]

24. Zhang, J.; Zhang, C.L.; Shi, W.L.; Fu, Y.C. Quantitative evaluation and optimized utilization of water resources-water environment carrying capacity based on nature-based solutions. J. Hydrol. 2019, 568, 96-107. [CrossRef]

25. Cheng, F.; Su, F.Z.; Chen, M.; Wang, Q.; Jiang, H.P.; Wang, X.G. An evolving assessment model for environmental carrying capacity: A case study of coral reef islands. J. Environ. Manag. 2019, 233, 543-552. [CrossRef]

26. Zhang, F.; Wang, Y.; Ma, X.J.; Wang, Y.; Yang, G.C.; Zhu, L. Evaluation of resources and environmental carrying capacity of 36 large cities in China based on a support-pressure coupling mechanism. Sci. Total Environ. 1991, 688, 838-854. [CrossRef]

27. Wang, Y.X.; Wang, Y.; Su, X.L.; Qi, L.; Liu, M. Evaluation of the comprehensive carrying capacity of interprovincial water resources in China and the spatial effect. J. Hydrol. 2019, 575, 794-809. [CrossRef]

28. Chi, M.B.; Zhang, D.S.; Fan, G.W.; Zhang, W.; Liu, H.L. Prediction of water resource carrying capacity by the analytic hierarchy process-fuzzy discrimination method in a mining area. Ecol. Indic. 2019, 96, 647-655. [CrossRef] 
29. Li, T.H.; Yang, S.N.; Tan, M.X. Simulation and optimization of water supply and demand balance in Shenzhen: A system dynamics approach. J. Clean. Prod. 2019, 207, 882-893. [CrossRef]

30. Wei, X.M.; Wang, J.Y.; Wu, S.G.; Xin, X.; Wang, Z.L.; Liu, W. Comprehensive evaluation model for water environment carrying capacity based on VPOSRM framework: A case study in Wuhan, China. Sustain. Cities Soc. 2019, 50, 101640. [CrossRef]

31. Yang, Z.Y.; Song, J.X.; Cheng, D.D.; Xia, J.; Li, Q.; Ahamad, M.I. Comprehensive evaluation and scenario simulation for the water resources carrying capacity in Xi'an city, China. J. Environ. Manag. 2019, 15, 221-233. [CrossRef]

32. Ma, X.L.; Ma, Y.J. The spatiotemporal variation analysis of virtual water for agriculture and livestock husbandry: A study for Jilin Province in China. Sci. Total Environ. 2017, 586, 1150-1161. [CrossRef]

33. Yang, B.G.; Liu, C.H.; Zai, Y.Z.; Li, H.M.; Wang, J.; Shang, J.C.; Ji, Y.M. The Principal Component Analysis of the River in Jilin Province. Sci. Geogr. Sinica 1986, 6, 261-268. (In Chinese)

34. Wang, H. The Future Situation of Water Resources in China and its Management Requirements. World Environ. 2011, 2, 16-17. (In Chinese)

35. Chen, H.F.; Hu, Y.A.; Zhao, J.F. Meeting China's Water Shortage Crisis: Current Practices and Challenges. Environ. Sci. Technol. 2009, 43, 240-244. [CrossRef]

36. Yu, G.Q.; Du, B.J.; Liu, J.P. Ecosystem Vulnerability Assessment of Wetlands in Western Jilin Province from 1986 to 2012. Wetland Sci. 2016, 14, 439-445. (In Chinese)

37. Zhang, W.F.; Zhang, H.; Zhao, J.J. Discussion on Water Resources in Jilin Province. J. China Hydrol. 2009, 29, 68-70.

38. Bian, J.Y.; Huang, C.S.; Geng, L.H.; Fang, R.; Wang, Y.K. Diagnostic System Construction of Water Resources Carrying Capacity and the Key Factors Determination. Water Sav. Irrig. 2019, 7, 56-61. (In Chinese)

39. Wang, B.H.; Lin, R.; Liu, D.C.; Feng, B.W. Investigation of the effect of humidity at both electrode on the performance of PEMFC using orthogonal test method. Int. J. Hydrog. Energy 2019, 44, 13737-13743. [CrossRef]

40. Wang, B.H.; Jin, Y.; Luo, Y.G. Parametric optimization of EQ6110HEV hybrid electric bus based on orthogonal experiment design. Int. J. Automot. Technol. 2010, 11, 119-125. [CrossRef]

41. Wang, H.; Yang, Z.; Saito, Y. Inter-annual and seasonal variation of the Huanghe (Yellow River) water discharge over the past 50 years: Connections to impacts from ENSO events and dams. Glob. Planet. Chang. 2006, 50, 212-225. [CrossRef]

42. Jiang, T.; Zhang, Q.; Zhu, D.; Wu, Y. Yangtze floods and droughts (China) and teleconnections with ENSO activities (1470-2003). Quat. Int. 2006, 144, 29-37.

43. Office of the South-to-North Water Diversion Project Construction Committee, State Council, PRC. The South-to-North Water Diversion Project. Engineering 2016, 2, 265-267. [CrossRef] 